\title{
Nursing Diagnosis Risk for falls: prevalence and clinical profile of hospitalized patients ${ }^{1}$
}

\author{
Melissa de Freitas Luzia $^{2}$ \\ Marco Antonio de Goes Victor ${ }^{3}$ \\ Amália de Fátima Lucena ${ }^{4}$
}

Objectives: to identify the prevalence of the Nursing Diagnosis (ND) Risk for falls in the hospitalizations of adult patients in clinical and surgical units, to characterize the clinical profile and to identify the risk factors of the patients with this ND. Method: a cross-sectional study with 174 patients. The data was collected from the computerized nursing care prescriptions system and on-line hospital records, and analyzed statistically. Results: the prevalence of the ND Risk for falls was $4 \%$. The patients' profile indicated older adults, males (57\%), those hospitalized in the clinical units (63.2\%), with a median length of hospitalization of 20 (10-24) days, with neurological illnesses (26\%), cardio-vascular illnesses (74.1\%) and various co-morbidities $(3 \pm 1.8)$. The prevalent risk factors were neurological alterations $(43.1 \%)$, impaired mobility $(35.6 \%)$ and extremes of age (10.3\%). Conclusion: the findings contributed to evidencing the profile of the patients with a risk of falling hospitalized in clinical and surgical wards, which favors the planning of interventions for preventing this adverse event.

Descriptors: Nursing Diagnosis; Accidental Falls; Nursing Care.

\footnotetext{
${ }^{1}$ Paper extracted from master's thesis "Análise do diagnóstico de enfermagem risco de quedas em pacientes adultos hospitalizados", presented to Escola de Enfermagem, Universidade Federal do Rio Grande do Sul, Porto Alegre, RS, Brazil. Supported by Fundo de Incentivo à Pesquisa, process \# 110631.

${ }^{2}$ MSc, RN, Hospital Ernesto Dornelles, Porto Alegre, RS, Brazil.

${ }^{3}$ Undergraduate student in Nursing, Escola de Enfermagem, Universidade Federal do Rio Grande do Sul, Porto Alegre, RS, Brazil.

${ }^{4}$ PhD, Adjunct Professor, Escola de Enfermagem, Universidade Federal do Rio Grande do Sul, Porto Alegre, RS, Brazil.
}

Corresponding Author: Melissa de Freitas Luzia Av. Ipiranga, $1801,10^{\circ}$ andar Bairro: Praia de Belas CEP: 90160-092 Porto Alegre, RS, Brasil Email: enfmel.luzia@gmail.com
Copyright (c) 2014 Revista Latino-Americana de Enfermagem This is an Open Access article distributed under the terms of the Creative Commons Attribution Non-Commercial License (CC BY-NC).

This license lets others distribute, remix, tweak, and build upon your work non-commercially, and although their new works must also acknowledge you and be non-commercial, they don't have to license their derivative works on the same terms. 


\section{Introduction}

A fall is the unintentional displacement of the body to a level lower than the initial level with incapability of correction in time, determined by multifactorial circumstances which compromise bodily stability ${ }^{(1)}$. Studies indicate that falls constitute one of the most prevalent adverse events in the hospital setting ${ }^{(2-3)}$, representing around $70 \%$ of the $\operatorname{cases}^{(3)}$, with rates varying from 1.4 to 10.7 falls for every 1000 patients/ day, depending on the hospital and on the type of patient. Falls can cause harm, increase clinical complications and the patients' duration of hospitalization, in addition to the hospital costs of their treatment ${ }^{(4-6)}$.

The majority of falls result in slight harm such as abrasions or bruises, however, in $20 \%$ to $30 \%$ of the cases, moderate or serious injuries occur, such as fractures of the femur or hip or cranial trauma, which cause physical limitations and disabilities, as well as increasing the risk of death(7). In addition to the physical damage, falls can also have psychological repercussions, expressed by the fear of falling again and by the loss of confidence in the ability to walk around safely, principally in the elderly, which can lead to a reduction in activities of daily living, a worsening of the functional decline, depression and social isolation ${ }^{(1)}$.

Hospitalized patients have a high risk of falls due to the unknown environment and the unfavorable clinical situation in which they find themselves, such as the presence of factors which are predictive of the event due to neurological illnesses, cardiovascular illnesses, urinary and/or intestinal incontinence, problems with balance, strength or vision, gait alterations, and adverse reactions to medications ${ }^{(8-9)}$.

Knowing this data, ensuring safe, quality care for hospitalized patients is one of the principal concerns of nursing, which has been appropriating strategies and practices for improving its care actions. An appropriate clinical judgment and the establishment of an accurate nursing diagnosis (ND) ${ }^{(10)}$ can trigger preventive measures, which allow the reduction of falls and the injuries resulting from these.

The nursing diagnoses (NDs), understood as scientific interpretations of the collected data, guide the planning and implementation of the interventions, so as to obtain the best results in health(11), as well as constituting fundamental elements for evidence-based nursing care, taking into account the patients' needs and safety ${ }^{(12)}$.
The NANDA-International (NANDA-I) defines the ND Risk for falls as "at risk for increased susceptibility to falling that may cause physical harm". The risk factors described for the same include those linked to the environment and the patients' cognitive and physiological state, as well as those caused by medication. They are also specified differently for adults and children ${ }^{(12)}$. Thus, the establishment of this ND, when appropriate, can support the nurse in the planning of preventive measures against this frequent adverse event.

Although various studies have been published on falls in different settings ${ }^{(13-16)}$, there remain very few investigating the application of the ND Risk for falls, which can constitute a tool for assisting in the qualification of the nursing care in this clinical situation. The investigations in existence on this ND are directed at specific populations such as the elderly ${ }^{(17)}$ and patients with specific pathologies(18-20); however, they do not address hospital contexts in a wider manner, in line with the distinct risk factors which this ND has. Moreover, there are few studies in actual clinical environments, with data from the clinical practice of the nursing staff, using this ND in their work routine, as happens in the institution which is the present investigation's field.

Thus, a gap is identified in the nursing knowledge on the ND Risk for falls, especially in hospitalized patients in clinical and surgical units, which covers the majority of the cases in a general hospital. Based on this, this study aimed: to identify the prevalence of the ND Risk for falls in the hospitalizations of adult patients in clinical and surgical units; to characterize the clinical profile of patients with this ND; and to identify their risk factors.

The study is also justified by the need to deepen knowledge on the ND Risk for falls, as it can guide and define the planning of interventions for preventing this event and, thus, contribute to patient safety.

\section{Method}

This cross-sectional study was undertaken in a large university hospital in the South of Brazil, with 795 beds, and which is in the process of hospital accreditation by the Joint Commission International. The Nursing Process is used in the institution as a method of work, is computerized, and has the stage of ND based in the NANDA-I terminology ${ }^{(12)}$.

The study population was the totality of hospitalizations of adult patients in the clinical and surgical units in 2011, which served as a basis for the 
calculation of the prevalence of the nursing diagnosis Risk for falls in this period. The data was obtained from the computerized system of managerial and nursing actions information.

For the study of the profile and the risk factors presented by the patients with the above-mentioned diagnosis, a sample of 174 patients was calculated, based on a previous study(21) undertaken in the institution, estimating the prevalence of the ND Risk for falls at $13 \%$ and considering a confidence interval of $95 \%$ with a margin of error of 0.05 .

The inclusion criteria were: adults hospitalized in the clinical and surgical units of the hospital with the ND Risk for falls established in the nursing care prescriptions. Patients who were hospitalized more than once in the study period were excluded, so that there would not be repetition of data from the same patient.

The data collection was retrospective in the computerized system of managerial information, nursing care prescriptions and on-line hospital records.

All the data was organized in Windows Excel worksheets and analyzed statistically with the assistance of the Statistical Package for the Social Sciences (SPSS) version 18.0 .

The research was approved by the institution's Research Ethics Committee, under Protocol N. 110631.

\section{Results}

In 2011, there were 13,135 hospitalizations of patients in the hospital's clinical and surgical units, with 521 hospitalizations of patients with the ND of Risk for falls established, according to information obtained by the institution's computerized system for managerial information and records of nursing care prescriptions. Based on this data, the prevalence of the ND Risk for falls was ascertained, which was presented in $4 \%$ of the cases.

Of the total of 521 hospitalizations of patients with the ND Risk for falls, analysis was undertaken of 174 different patients who made up the sample for the study of the clinical profile of the same. Among the results, the mean age was $68 \pm 13.7$ years old, the majority were males, and the mean length of inpatient treatment was 20 (10-24) days, on most occasions in the clinical units. Among these patients' most frequent co-morbidities, one finds the cardiovascular, endocrine and neurological diseases. The mean number of co-morbidities per patient was $3 \pm 1.8$ (Table 1 ).
Table 1 - Characteristics and co-morbidities in patients with Nursing Diagnosis Risk for Falls, hospitalized in clinical and surgical units. Porto Alegre, State of Rio Grande do Sul (RS), Brazil, $2012(\mathrm{~N}=174)$

\begin{tabular}{|c|c|}
\hline Variables & $f(\%)$ \\
\hline Age (years) ${ }^{*}$ & $68.5 \pm 13.7$ \\
\hline Sex (male) & $99(56.9)$ \\
\hline Length of hospitalization (days) ${ }^{\dagger}$ & $20(10-24)$ \\
\hline Hospitalized in clinical unit & $110(63.2)$ \\
\hline Cardiovascular diseases & $129(74.1)$ \\
\hline Endocrine diseases & $81(46.5)$ \\
\hline Neurological diseases & $49(28.1)$ \\
\hline Neoplastic diseases & $28(16.1)$ \\
\hline Renal/urinary diseases & $27(15.5)$ \\
\hline Smoking & $22(12.6)$ \\
\hline Gastrointestinal tract diseases & $17(9.8)$ \\
\hline Respiratory diseases & $15(8.6)$ \\
\hline Rheumatological diseases & $13(7.5)$ \\
\hline Infectious-contagious diseases & $13(7.5)$ \\
\hline Vascular diseases & $9(5.2)$ \\
\hline Alcoholism & $6(3.4)$ \\
\hline
\end{tabular}

In addition to the data described previously, it was also verified that the principal reasons for these patients' hospitalization were neurological (25.9\%), neoplastic $(14.9 \%)$, cardiovascular $(13.8 \%)$, and respiratory diseases (12.6\%).

The risk factors for the ND Risk for falls available in the computerized system for nursing care prescriptions in the institution researched are: Environmental conditions, Neurological alteration, Impaired mobility, Adverse effects of medication, Extremes of age, and Physiological changes. All these factors were used for establishing the ND Risk for falls in the patients studied, but the most frequent of them was Neurological alteration (Table 2).

Table 2 - Risk factors identified for the Nursing Diagnosis Risk for Falls. Porto Alegre, RS, Brazil, 2012 ( $N=174)$

\begin{tabular}{lcc}
\hline $\begin{array}{c}\text { Risk Factors for the Nursing Diagnosis Risk } \\
\text { for Falls }\end{array}$ & $\mathbf{f}$ & $\mathbf{( \% )}$ \\
\hline Neurological alteration & 75 & 43.1 \\
Impaired mobility & 62 & 35.6 \\
Extremes of age & 18 & 10.3 \\
Physiological changes & 11 & 6.3 \\
Adverse effects of the medication & 4 & 2.3 \\
Environmental conditions & 4 & 2.3 \\
Total & 174 & 100 \\
\hline
\end{tabular}

\section{Discussion}

The study evidenced a low prevalence (4\%) of the ND Risk for falls in the hospitalizations of patients in 
the clinical and surgical units in 2011. In another study undertaken in the same institution, held however with patients who had suffered falls from hospital beds, the prevalence of the ND Risk for falls was $13 \%(21)$. This difference may be related to the fact of the ND having been established after the event of the fall, as the history of previous falls is considered as a risk for further events $^{(9)}$.

Rather differently, the ND Risk of Falls had a prevalence of $46.7 \%$ in an investigation undertaken in a hospital located in Southeast Brazil, accredited by the Joint Commission International. Since then, this hospital has used a protocol for establishing this ND, standardized nursing care prescriptions, and previous training in this issue of the nurses directly involved in care ${ }^{(22)}$.

These differing data on the prevalence of the ND Risk for falls may be related to the time being experienced in each of the institutions studied. One is in the process of hospital accreditation - the case of the setting of the current study - and the other is already accredited and using the protocol for the prevention of falls. From this, it may be inferred that the process of evaluation instituted by the process of hospital accreditation may have influenced the assistential context and the nursing management, as a higher prevalence of the ND Risk for falls was ascertained after the implantation of the systematized measures for prevention of falls in the accredited hospital. The activities for training of the team and implantation of the falls prevention protocol probably favored the evaluation and identification of the risk of falls in the patients and, therefore, provided greater support for establishing the ND Risk for falls.

The hospital institutions' involvement in the process of certification in health encourages discussions on the questions of safety, and guides the development of strategies which allow the health professionals to identify and reduce the risks to which the patients are exposed during their inpatient treatment, which is reflected in better quality care. One study on the results of a protocol for the management of falls, implanted in a private Brazilian hospital, evidenced that the process of accreditation guided the putting into effect of the preventive actions and guided the monitoring of the indicator of care quality 'incidence of falls' in the institution(6).

Another issue to be taken into account regarding the prevalence of the ND Risk for falls in the hospitalizations is the characteristics of the population studied. Investigations with specific populations, such as that of patients with unstable angina, or older adults who experienced cerebro-vascular accidents, demonstrated prevalences of $87.71 \%$ and $100 \%$, respectively, far higher than the data found in this study ${ }^{(18-19)}$. This higher prevalence of the ND Risk for falls verified in these investigations is probably related to the fact that the populations studied presented specific characteristics which make them more susceptible to the occurrence of falls, hence the importance of also studying patients hospitalized in clinical and surgical units, with different reasons for their hospitalization.

On the other hand, it is necessary to consider that the low prevalence of the ND Risk for falls found in this investigation may also be associated with the fact of the nurses not having identified the risk factors for this ND and, therefore, not having established it. This indicates the importance of using an instrument for evaluating the risk for falling, which may facilitate the identification of the most vulnerable patients, as with the recommendations of NANDA-I ${ }^{(12)}$ for establishing the ND Risk for Impaired Skin Integrity.

The clinical profile of the patients with the ND Risk for falls in this study was mainly of elderly patients, male, hospitalized in the clinical units, with a prolonged duration of inpatient treatment, with neurological or cardiovascular diseases, and with various co-morbidities.

The proportion of older adults (people over 60 years of age, according to Brazilian legislation) is growing in Brazil and worldwide, due to lower levels of fertility and the increase in life expectancy at birth. The highest proportions of older adults are found in the Southeast, South, and Northeast regions of Brazil. In the state of Rio Grande do Sul, $13 \%$ of the population is elderly(23). It is known that advanced age is considered a risk factor for falls and for injuries resulting from them, due to the changes caused by the physiological process of aging. In this phase of life, the problems of physical mobility, postural instability, gait alteration, and reduction of functional, cognitive and visual capacity are predictive factors for falls. Apart from this, the chronicdegenerative diseases, and the concomitant use of various medications, are common conditions in older adults, which can also increase the risk of falling and the seriousness of the injury resulting from the fall(6,13-14).

The risk factor related to age is also described in the NANDA-I classification(12) for the ND Risk for falls, where it is termed "Age 65 or older", and in the nursing actions system of the institution researched, where it is termed "Extremes of age". Thus, elderly patients need to receive special attention during the nurse's evaluation, which seeks information regarding changes 
resulting from aging, on previous illnesses and the use of medications related to an increased risk of falls.

Regarding the patients' sex, the study evidenced that the majority were male. There is no consensus in the literature either on which sex is more associated with the risk of falls, or on whether this is a factor to be considered, given that some studies present a greater incidence of falls among men ${ }^{(2,13-14,21)}$ and others, among women ${ }^{(5,15,24)}$. The studies which indicate men address cultural questions, in which men request less help for undertaking activities of daily living ${ }^{(21)}$; in addition to this, the predominance of women in nursing may influence the male patient's decision not to request help ${ }^{(2)}$.

The considerations on women and the increased risk of falls refer to the higher prevalence of osteoarthritis in women, reduction in muscle mass strength, their greater link with domestic activities and hormonal changes such as reduction of estrogen, with consequent loss of bone mass. In addition to this, the female population is higher than that of men in Brazil, their life expectancy is greater, and, therefore, they suffer more from the changes resulting from aging $(15,19)$.

Until the 2005-2006 edition of NANDA-I(12), being female was considered a risk factor in adults for the ND Risk for falls; however, the diversity of the findings in the literature related to gender and falls must have influenced the removal of this factor from the edition of the book which followed (2007-2008)(12). Thus, as it is a broad issue, dependent on the social and cultural context and on the type of population being studied, it does not seem appropriate to consider gender as a risk factor for falls in isolation.

The majority of patients with the ND Risk for falls are hospitalized in the hospital's clinical units, similarly to the findings of other studies ${ }^{(5-6,14,21)}$, which also note that the patients from the clinical units, when compared to those from the surgical units, present a longer duration of inpatient treatment, a higher number of co-morbidities and advanced age, which can increase their risk of falls(6).

These factors are also shown to be important in the present study, as the majority of the patients with the ND Risk for falls were hospitalized in clinical units, were elderly, and - mainly - had neurological and/or cardiovascular diseases, as well as a mean of three comorbidities.

Neurological diseases such as Parkinson's, cerebrovascular accidents and epilepsy, and the cardiovascular conditions, such as arrhythmias and cardiac insufficiency, cause changes in the patients, resulting from the physiopathological process and treatment, which are often associated with the occurrence of falls ${ }^{(2)}$.

Neurological patients generally present changes in the level of consciousness, impaired mobility, sensory changes, orthostatic hypotension, and vesical or intestinal changes, factors which make them more susceptible to falls ${ }^{(19)}$. Patients with cardiovascular disorders also present a relationship with the risk of falling, as reduced cardiac output can lead to a reduction in the cerebral flow and cognitive decline, considered a risk factor for falling. Other symptoms characteristic of the cardiovascular diseases, such as dizziness, vertigo, dyspnea and nausea can also increase susceptibility to the occurrence of the event, as described in a study which found association between risk of falling and the presence of unstable angina, arterial hypertension, and vascular disease ${ }^{(18)}$.

Besides these signs and symptoms, the medications frequently used in patients with neurological and cardiovascular diseases (anti-hypertensives, antiparkinsonians, anxiolytics and hypnotic agents) can also present effects significantly associated with an increased risk of falls in the hospital environment ${ }^{(14,18)}$. With the exception of the anti-parkinsonians, the use of all the above-mentioned medications is described in NANDA-I as a risk factor for the ND Risk for falls ${ }^{(12)}$, being important data to be investigated by the nursing personnel.

The main risk factors related to the ND Risk for falls evidenced in this study were Neurological alteration (43.1\%), Impaired mobility (35.6\%) and Extremes of age $(10.3 \%)$. These risk factors meet the patients' profile: older adults (mean age of $68.5 \pm 13.7$ years old) and with neurological diseases (principal reason for hospitalization) and cardiovascular diseases (principal comorbidity). Similar results are described in the literature, which indicates as the principal factors for risk of falling: impaired balance, difficulties in walking, impaired physical mobility, age over 60 years, proprioceptive deficit, reduced mental state and medications which alter the central nervous system $(6,19,21)$.

The risk factor Neurological alteration may be related to cognitive decline, considered a strong indicator for falls, in particular in the old (Extremes of age), as it causes difficulties in undertaking activities of daily living, disorientation in time and space, gait changes, and changes in postural stability (Impaired mobility) ${ }^{(19)}$. These risk factors may be present in an associated way in the patients and thus may increase the individual's susceptibility to falling. 
A fall is an event with a multifactorial character, which makes the evaluation of its risk a complex process. The greater the number of risk factors present, the higher the individual's probability of falling, which does not discard the hypothesis that the presence of just one factor, but with a high degree of compromise, can also lead to a fall(16)

Thus, the evaluation of the patient undertaken by the nurse is a fundamental stage in the prevention of falls, as through the collection of data and the application of a predictive scale, it is possible to identify the presence of risk factors for this event and - based on this - to establish an accurate ND, and the appropriate preventive interventions.

\section{Conclusions}

The analysis of the ND Risk for falls in patients who are hospitalized in clinical and surgical units demonstrated a low prevalence of the same in the institution researched. It is known that in the study period, a protocol for the evaluation of the risk of falling was not being used in the institution, which may have influenced the low prevalence of this ND.

Regarding the profile of the patients with the ND Risk for falls, what was found was: a majority of older adults, male, with prolonged hospitalization in, most of the time, clinical units. They were, principally, patients with neurological and cardiovascular diseases, and with various co-morbidities, whence it is concluded that they were significantly vulnerable to the adverse event of a fall.

The principal risk factors identified for the ND Risk for falls were Neurological alteration, Impaired mobility, and Extremes of age, which corroborates this vulnerability of the patients, associated with their physical condition and impaired health.

Thus, it is fundamental for the nurse to investigate and know the patients' clinical characteristics, as well as which of these are related to greater susceptibility to falls, so as to accurately identify the ND Risk for falls. This, once established, guides the planning of effective interventions for the prevention of the event and for the promotion of the patient's safety.

\section{Acknowledgments}

Professor Miriam de Abreu Almeida, coordinator of the Paraquedas (Parachutes) Project, for making possible and encouraging the undertaking of various studies based on this large project.

\section{References}

1. Pereira SRM, Buksman S, Perracini M, Py L, Barreto KML, Leite VMM. Sociedade Brasileira de Geriatria e Gerontologia. Projeto Diretrizes. Quedas em idosos. São Paulo: Associação Médica Brasileira, Conselho Federa de Medicina; 2001.

2. Paiva MCMS, Paiva SAR, Berti HW. Eventos adversos: análise de um instrumento de notificação utilizado no gerenciamento de enfermagem. Rev Esc Enferm USP. 2010 [acesso 30 out 2012]; 44(2):287-94. Disponível em: http://www.scielo.br/pdf/reeusp/v44n2/07.pdf 3. Carneiro FS, Bezerra ALQ, Silva AEBC, Souza LP, Paranaguá TTB, Branquinho NCSS. Eventos adversos na clínica cirúrgica de um hospital universitário: instrumento de avaliação da qualidade. Rev Enferm UERJ. 2011 [acesso 25 out 2012]; 19(2):204-11. Disponível em http://www.facenf.uerj.br/v19n2/v19n2a06.pdf

4. Abreu C, Mendes A, Monteiro J, Santos FR. Quedas em meio hospitalar: um estudo longitudinal. Rev. LatinoAm. Enfermagem. 2012;20(3):597-603.

5. Schwendimann R, Buhler $H$, De Geest S, Milisen K. Characteristics of hospital inpatient falls across clinical departments. Gerontology. 2008;54(6):342-8.

6. Correa AD, Marques IAB, Martinez MC, Laurino OS, Leão ER, Chimentão DMN. Implantação de um protocolo para gerenciamento de quedas em hospital: resultados de quatro anos de seguimento. Rev Esc Enferm USP. 2012 [acesso 30 out 2012]; 46(1):67-74. Disponível em: http://www.scielo.br/pdf/reeusp/v46n1/v46n1a09.pdf

7. Centers for Disease Control and Prevention. National Center for Injury Prevention and Control. Falls among older adults: an overview. Atlanta: CDC [Internet] 2011 [acesso 23 out 2012] Disponível em: http://www.cdc. gov/HomeandRecreationalSafety/Falls/adultfalls.htm

8. Healey F, Darowski A, Lamont T, Panesar S, Poulton S, Treml J, et al. Essential care after an inpatient fall: summary of a safety report from the National Patient Safety Agency. BM]. 2011 [acesso 24 set 2012]; 342: d329. Disponível em: http://dx.doi.org/10.1136/bmj.d329

9. Deandrea S, Lucenteforte E, Bravi F, Foschi R, La Vecchia C, Negri E. Risk factors for falls in communitydwelling older people: a systematic review and metaanalysis. Epidemiology. 2010;21(5): 658-68.

10. Almeida MA, Lucena AF, Franzen E, Laurent MCR. Processo de enfermagem na prática clínica: estudos clínicos realizados no Hospital de Clínicas de Porto Alegre. Porto Alegre: Artmed; 2011. 320 p.

11. Lunney M. Coleta de dados, julgamento clínico e diagnóstico de enfermagem: como determinar 
diagnósticos precisos. In: NANDA International. Diagnósticos de enfermagem da NANDA: definições e classificações 2012 - 2014. Porto Alegre: Artmed; 2013. p.112-33.

12. NANDA International. Diagnósticos de enfermagem da NANDA: definições e classificação 2012 - 2014. Porto Alegre: Artmed; 2013. 606 p.

13. Lakatos BE, Capasso V, Mitchell MT, Kilroy S, Cushing $M L$, Sumner $L$, et al. Falls in the general hospital: association with delirium advanced age, and specific surgical procedures. Psychosomatics. 2009 [acesso 20 out 2012]; 50(3):218-26. Disponível em: http://psy. psychiatryonline.org

14. Shuto $H$, Imakyure O, Matsumoto J, Egawa T, Jiang $Y$, Hirakawa $M$, et al. Medication use as a risk factor for inpatient falls in an acute care hospital: a case-crossover study. BJCP. 2010 [acesso 20 out 2012]; 69(5):53542. Disponível em: http://www.ncbi.nlm.nih.gov/pmc/ articles/PMC2856055/pdf/bcp0069-0535.pdf

15. Alvares LM, Lima RC, Silva RA. Ocorrência de quedas em idosos residentes em instituições de longa permanência em Pelotas, Rio Grande do Sul, Brasil. Cad Saúde Pública. 2010 [acesso 30 out 2012]; 26(1):31-40. Disponível em: http://www.scielo.br/pdf/csp/v26n1/04.pdf

16. Paula FL, Fonseca MJM, Oliveira RVC, Rozenfeld S. Perfil de idosos com internação por quedas nos hospitais públicos de Niterói (RJ). Rev Bras Epidemiol. [Internet]. 2010 [acesso 10 set 2012]; 13(4):587-95. Disponível em: http://www.scielo.br/pdf/rbepid/v13n4/04.pdf

17. Marin MJS, Amaral FS, Martins IB, Bertassi VC. Identificando os fatores relacionados ao diagnóstico de enfermagem "risco de quedas" entre idosos. Rev Bras Enferm. 2004 [acesso 20 out 2012]; 57(5): 560-4. Disponível em: http://www.scielo.br/pdf/reben/v57n5/ a09v57n5.pdf

18. Vitori AF, Lopes MVO, Araújo TL. Diagnóstico de enfermagem risco de quedas em pacientes com angina instável. Rev Rene. 2010 [acesso 22 out 2012]; 11(1):105-13. Disponível em: http://www.revistarene. ufc.br/vol11n1_html_site/a11v11n1.htm

19. Morais HCC, Holanda GF, Oliveira ARS, Costa AG, Ximenes CMB, Araujo TL. Identificação do diagnóstico de enfermagem "risco de quedas" em idosos com acidente vascular cerebral". Rev Gaúcha Enferm. 2012 [acesso 10 out 2012]; 33(2):117-24. Disponível em: http:// seer.ufrgs.br/RevistaGauchadeEnfermagem/article/ view/20217/19501

20. Costa AGS, Oliveira ARS, Moreira RP, Cavalcanti TF, Araújo TL. Identificação do risco de quedas em idosos após acidente vascular encefálico. Esc Anna Nery. 2010 [acesso 1 nov 2012]; 14(4): 684-9. Disponível em: http://www.scielo.br/pdf/ean/v14n4/v14n4a05.pdf

21. Costa SGRF, Monteiro DR, Hemesath MP, Almeida $M A$, et al. Caracterização das quedas do leito sofridas por pacientes internados em um hospital universitário. Rev Gaúcha Enferm. 2011 [acesso 10 out 2012]; 32(4): 676-81. Disponível em: http:// seer.ufrgs.br/RevistaGauchadeEnfermagem/article/ view/18753/14441

22. Lasta NS, Fernades VA, Silva DP, Vigo LR, Batista AS, Friedrich $N$. Diagnóstico de enfermagem risco de queda: ferramenta facilitadora na implantação do protocolo de queda. In: $10^{\circ}$ Simpósio Nacional de Diagnóstico de Enfermagem; 04-07 agosto 2010; Brasília, Distrito Federal. Brasília: ABEn; 2010. p. 430-3.

23. Ministério da Saúde (BR). DATASUS. Indicadores Demográficos: proporção de idosos na população-2009. [acesso 21 out 2012]. Disponível em: http://www2. datasus.gov.br.

24. Krauss MJ, Nguyen SL, Dunagan C, Birge S,

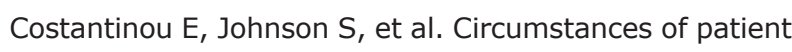
falls and injuries in 9 hospitals in Midwestern healthcare system. Infect Control Hosp Epidemiol. 2007. [acesso 10 out 2012];28(5):544-50. Disponível em: http:// www.ccih.med.br/m/aluno/mod/biblioteca_virtual/ revistas_2007/infection_control_hospital_epidemiology/ Maio/544.pdf
Received: Apr. 19 2013 Accepted: Nov. 14 $4^{\text {th }} 2013$ 